\title{
THE FUTURE OF COMMUNITY RESPONSIBILITY
}

\author{
Rt Hon Sir Geoffrey Palmer*
}

This paper considers the future of community responsibility - the central philosophical principle of the 1967 Report of the Royal Commission concerning compensation for personal injury in New Zealand (the Woodhouse Report). Central to the Report was the advancement of earnings-related benefits free of all income or means test. Community responsibility was developed by the Royal Commission as the entire basis and principle for its recommendations. This principle has been traced to international instruments like the Universal Declaration of Human Rights. The Australian Woodhouse report proposed a similar version of the principle but the response in the two countries differed. In Australia it was argued that collective responsibility would be the death of individualism whereas in New Zealand the principle was never really attacked and was not seen as alien to the country's culture. A problem with the notion of community responsibility in both reports is that it is difficult to see how to limit it. In New Zealand the responsibility was restricted to injuries and not extended to sickness, which creates glaring social inequalities and discrimination. However it seems unlikely that this situation will change in the immediate future because of the lack of public disquiet about the issue. In the future, policy in the area may be affected by human rights norms which conflict with the current situation where eligibility for support is based on the manner in which the disability was acquired.

I am invited to consider the future of community responsibility, a central philosophical principle of the Woodhouse Report. It is impossible to consider the future of the concept of community responsibility without examining its past. Oliver Wendell Holmes Jr said in 1881: ${ }^{1}$

* Consultant, Chen Palmer and Partners, Barristers and Solicitors, Public Law Specialists, Wellington.

1 Oliver Wendell Holmes The Common Law (M DeWolfe Howe (ed), Little Brown, Boston, 1963) 77. This passage was also thought to be sufficiently important to be reproduced in Richard A Posner (ed) The Essential Holmes - Selections from the Letters, Speeches, Judicial Opinions, and Other Writings of Oliver Wendell Holmes Jr (University of Chicago Press, Chicago, 1992) 256. 
The state might conceivably make itself a mutual insurance company against accidents, and distribute the burden of its citizens' mishaps amongst all its members. There might be a pension for paralytics, and state aid for those who suffered in person or estate from tempest or wild beasts. As between individuals it might adopt the mutual insurance principle pro tanto, and divide damages when both were in fault, as in the rusticum judicium of the admiralty, or it might throw all loss upon the actor irrespective of fault. The state does none of these things, however, and the prevailing view is that its cumbrous and expensive machinery ought not to be set in motion unless some clear benefit is to be derived from disturbing the status quo. State interference is an evil, where it cannot be shown to be a good. Universal insurance, if desired, can be better and more cheaply accomplished by private enterprise.

Holmes was probably the greatest American lawyer who ever lived. He was extraordinarily open-minded. New Zealand's accident compensation scheme expressed what Holmes thought was a mere possibility for accident compensation legislation. It will not have escaped the attention of this audience that coverage could just as well be extended to sickness and the statement from Holmes would be equally valid. In New Zealand the State has done those things which Holmes did not think it would do or should do. Some may seek to undo them but the essential features of the accident compensation scheme are now thirty years old in New Zealand legislation and have repelled several attempts to overthrow them. The abandonment of the system of legal remedies for personal injury provided by the common law of torts is the emblematic element of the reform.

It may be important to root the origins of the idea to the famous Holmes book The Common Law $^{2}$ because accident compensation was and always has been a legal reform. But it is not a humble legal reform; it has Messianic tendencies. And it is that to which the notion of community responsibility is directed. The ultimate issues in the New Zealand accident compensation reforms were not about the law. They were about values. They concerned social priorities. The choices were political. The debate was about which matters should be handled as a matter of collective community decision and which matters are best left to the market to be dealt with on a commercial basis. Such choices are always difficult and fashions vary on the desirability of intervention grappling with such issues and providing analysis of them is one of the essential tasks of economics.

The central core of the Woodhouse Reports in both New Zealand and Australia comprised earnings-related benefits free of all income or means test. In part, the benefits were a legacy from the common law, the destruction of which could not be properly allowed unless the substitute was comparable in money terms. Whether such principles are the appropriate ones upon which to build the whole pattern of income maintenance is an issue upon which the jury is still out. Many would say extending earnings-related compensation available to the victims of injury to the entire income maintenance system would produce a welfare state too distended and expensive, replete with issues

2 Holmes, above $n 1$. 
of moral hazard. It will sap the vigour of those whom it is designed to help. That is not a view that I accept.

The Woodhouse Report was based on an optimistic vision that the achievement of real security was important for building a better society. Community responsibility was developed by the Royal Commission as the entire basis and principle upon which its recommendations were based. That principle was stated in the Woodhouse Report: ${ }^{3}$

First, in the national interest, and as a matter of national obligation, the community must protect all citizens (including the self-employed) and the housewives who sustain them from the burden of sudden individual losses when their ability to contribute to the general welfare by their work has been interrupted by physical incapacity ....

Note that principle is not restricted to personal injury by accident. It includes all physical incapacity. That was a deliberate decision by the author of those words, Sir Owen Woodhouse. It is to be observed that that principle could be traced to instruments such as the Universal Declaration of Human Rights. Indeed, Dr Colin Aikman, the New Zealand Delegate to the United Nations Conference on the Universal Declaration of Human Rights in Paris in 1948 said: ${ }^{4}$

My delegation ... attaches equal importance to all the articles .... . At the same time we regard with particular satisfaction the place which is given in the declaration to social and economic rights. Experience in New Zealand has taught us that the assertion of the right of personal freedom is incomplete unless it is related to the social and economic rights of the common man. There can be no difference of opinion as to the tyranny of privation and want. There is no dictator more terrible than hunger. And we have found in New Zealand that only with social security in its widest sense can the individual reach his full stature. Therefore it can be understood why we emphasize the right to work, the right to a standard of living adequate for health and well-being, and the right to security in the event of unemployment, sickness, widowhood and old age. Also the fact that the common man is a social being requires that he should have the right to education, the right to rest and leisure, and the right to freely participate in the cultural life of the community.

These social and economic rights can give the individual the normal conditions of life which make for the larger freedom. And in New Zealand we accept that it is the function of government to promote their realization.

3 New Zealand Royal Commission of Inquiry into Compensation for Personal Injury Compensation for Personal Injury in New Zealand: Report of the Royal Commission of Inquiry (Government Printer, Wellington, 1967) para 55 ["Woodhouse Report”].

4 Colin Aikman "New Zealand and the Origins of the Universal Declaration" (1999) 29 VUWLR 1, 5. 
The same Colin Aikman, when Dean of the Faculty of Law at Victoria University of Wellington, provided help to the Royal Commission chaired by Sir Owen Woodhouse. Professor Aikman, Professor I L M Richardson, Mr K J Keith and Mr P D McKenzie appeared at the second set of the hearings of the Royal Commission. Their submissions bore a startling resemblance to the ideas contained in the final Report of the Commission. ${ }^{5}$ They were responding to a submission that had been made by the Department of Social Security at the first set of hearings of the Royal Commission. The Department had submitted a carefully researched set of submissions on each of the matters itemised in the Terms of Reference. The Department regarded both common law damages and workers' compensation in a most unfavourable light. It preferred periodic payments. The Department wanted a pension scheme to replace common law and workers' compensation. The scheme was to be run by the Department. But the problem arose about the necessity of thinking about social welfare problems as a coherent whole. Professor Aikman said this to the Royal Commission: ${ }^{6}$

I believe there is a community responsibility to see that all persons who suffer from any disability whether it arises from accident, sickness or any other cause - receive a satisfactory standard of care and support that will enable them as soon as possible to assume, or resume, their full places as members of the community or, if the disability is of a permanent character, will enable them to live as useful and as comfortable lives as their disability permits.

The submission of the academic lawyers called for the abolition of the common law. The compensation payments were to be periodic. ${ }^{7}$

It is interesting to reflect upon the possible connection between the Universal Declaration of Human Rights and the community responsibility principle that drove the 1967 Royal Commission's report. Article 25(1) of the Declaration provides: ${ }^{8}$

Everyone has the right to a standard of living adequate for the health and well-being of himself and of his family, including good clothing, housing and medical care and necessary social services, and the right to security in the event of unemployment, sickness, disability, widowhood, old age or other lack of livelihood in circumstances beyond his control.

5 It might be observed that it was not a bad group of academics either.

6 As quoted in Geoffrey Palmer Compensation for Incapacity: A Study of Law and Social Change in New Zealand and Australia (Oxford University Press, Wellington, 1979) 71, n 24 ["Compensation for Incapacity"].

7 The background to the making of the submission is well described in Peter McKenzie QC "The Compensation Scheme No One Asked For: the Origins of ACC in New Zealand" (2003) 34 VUWLR 193, 200.

8 Universal Declaration of Human Rights UNGA Resolution 217A (III) (10 December 1948), art 25(1). 
In 2004 we perhaps cannot easily recall the determination of those generations who experienced the Second World War to make the world a better place and to use the power of the State to promote conditions of social justice that may prevent conditions that foster wars from arising. But it could be argued that Article 25 does not itself provide a basis for that feature of the Royal Commission's report that brings about a clash in New Zealand with the income maintenance benefit system - the earnings-related compensation feature. There is a big difference between a system of flat-rate benefits emanating from the Social Security Act 1964 and earnings-related accident compensation going up to quite high levels of income. Not the least part of the difference lies in the fiscal effects. But it needs to be remembered that the justification for the difference was argued powerfully in the 1967 Report and gained acceptance. The point that the writer has been pondering ever since 1967 is why the principle did not migrate. And the explanation for that may lie in the great debate in superannuation that erupted in 1975 and has been a point of political contention ever since. The generous and universal programme for the aged used up the available money and simply removed the relationship of accident compensation to the system of categorical benefits from the agenda.

The Royal Commission in 1967 outlined a sensible but warm-hearted set of ideas which would inspire the reader with a sense of vision. Everyone was to be looked after - it was the community's responsibility to do it. Beneath the idea lurked a definitely collectivist set of values. The values assume the legitimacy of a large area for state action, the justifications for which were never really argued.

The elegance with which the idea was stated tended to conceal its content. Yet the idea was never attacked in New Zealand. As a statement of the New Zealand ethos, it was an accurate although new formulation of a sort of community consensus. The view needed to be captured and stated, but it was not a value alien to the culture. Things may have changed in this regard since 1967 and it would be surprising if they had not. For many years accident compensation was a matter of bi-partisan agreement between the main political parties National and Labour. That agreement was fractured by the 1992 reforms and has yet to be restored. On coming to office in 1999 Labour restored the traditional elements of the scheme and removed the element of private insurance that had been implemented by the National Government.

The idea of community responsibility was expressed in similar terms in the Australian Woodhouse Report. It was attacked in the Parliamentary debates in that country as being the death of individualism. That may reflect something about the respective political cultures of Australia and New Zealand at the time, a time when both countries had Labour Governments. A reform that springs from a stated social value with which people feel comfortable can secure legitimacy. And that was the heavy political lifting that community responsibility performed for the 1967 Royal Commission.

The politicians themselves, while essentially pragmatic as all New Zealand politicians tend to be, did understand the political ideology expressed. Mr E E Isbey, a Labour MP and former Trade 
Union Secretary, regarded the Woodhouse Report as expressing the term "community responsibility as another term for democratic socialism". ${ }^{9}$

The fate of the Woodhouse Report in Australia was very different from that which greeted the Royal Commission's Report in New Zealand. The central core of the reform proposals was the same in Australia and New Zealand, but variations were made to suit Australian conditions. The first two paragraphs of the Woodhouse Report in Australia set its tone: ${ }^{10}$

This Report is concerned with the responsibility of society for the injured and the sick. Its theme is their need for automatic rehabilitation and compensation - without tags and without discrimination. The recommendation is for generous earnings-related compensation at every level of income up to $\$ 26,000$ per annum. In consequence, the present social security system of pensions that aims merely at an income for subsistence would need to be replaced. At the same time a new scheme would supplant the actions at law based on fault. And the general system of workers' compensation would disappear. In the absence of the risks relating to those remedies there would, of course, no longer be a basis for any form of compulsory insurance.

Social problems in the past have been handled in a piecemeal fashion. But half-measures and compromise are quite incapable of meeting the modern needs and reasonable aspirations of disadvantaged citizens. The obligations of the community should be thought through from first principles. The Report attempts to provide that analysis. It proposes a new deal for every Australian whose life has been disrupted or damaged by injury or disease.

Notice that in the Australian Report the problem of sickness and disease was confronted directly and deliberately. But it needs to be borne in mind that in Australia the Inquiry did not start with having a Terms of Reference that extended to sickness and disease. The Terms of Reference for the Australian Inquiry were announced in March 1973. They were designed to make it clear that some of the important questions had been decided by the Government in advance. Those Terms of Reference stated that the Australian Government had agreed in principle to establish a National Compensation Scheme: ${ }^{11}$

9 Compensation for Incapacity, above n 6, 81.

10 National Committee of Inquiry on Compensation and Rehabilitation in Australia National Rehabilitation and Compensation Scheme Committee: Report of the National Committee of Inquiry on Compensation and Rehabilitation in Australia (Vol 1, Australia Government Publishing Service, Canberra, 1974) paras 1 and 2.

11 The full Terms of Reference are set out in Compensation for Incapacity, above n 6, 134. 
For the purpose of rehabilitating and compensating every person who at any time suffers a personal injury (including pre-natal injury) and whether the injury be sustained on the road, at work, in the home, or in the school or elsewhere or is an industrial disease ....

But it had already been in Sir Owen Woodhouse's mind that it would be worthwhile extending the Inquiry's Terms of Reference to sickness if an examination of the figures showed that that might be done within reasonable cost. A great deal of work was done in the Inquiry on the statistical costing of a combined sickness and accident scheme. The Inquiry provided advice to the Government which, on 1 February 1974, announced an extension of the Terms of Reference in the following terms: ${ }^{12}$

And to further inquire into and report on an extension of the scheme for the purpose of rehabilitating and compensating every person who suffers a physical or mental incapacity or deformity by reason of sickness or congenital defect, together with the application of the scheme where death results from such sickness or defect.

In the Final Report, the recommendations on sickness were drafted in a self-contained part that could be taken out and, with the wisdom of hindsight, it might have been better if the Inquiry had got on with its job in the injury area without all the delays that the sickness extension to the Terms of Reference caused. In that way, a scheme may well have been enacted before the Whitlam Government fell.

But the Australian version of the principle of community responsibility was similar in many respects to that in New Zealand. It was as follows: ${ }^{13}$

There is the initial principle of community responsibility. For three main reasons the community must accept the obligations that are clearly owed to every person who has been struck down by sickness or by injury. First there are the civilised reasons of humanity. Next, there are the economic reasons of selfinterest. If the well-being of the workforce is neglected the economy soon will suffer injury and society itself thus has much to lose. Finally, there is the plain fact that rights universally enjoyed must be accompanied by obligations universally accepted. The scheme proposed is a national scheme. It involves national responsibility. It must be organised as a responsibility of the State.

It is worth recording the opinion of Professor Harold Luntz, expressed at the 2002 Conference on Accident Compensation that: ${ }^{14}$

12 Compensation for Incapacity, above n 6, 135.

13 National Rehabilitation and Compensation Scheme Committee of Inquiry, above n 10, para 256.

14 Harold Luntz "Looking Back at Accident Compensation: An Australian Perspective" (2003) 34 VUWLR 279, 292. 
No longer does the Woodhouse Report call for 'community responsibility' resonate among politicians and the public.

Well, that may be true in Australia, but I am not so sure that it is true in New Zealand, although we went through periods when it threatened to be. The problem of course with the notion of community responsibility as stated in both Woodhouse Reports is that it is difficult to see what limits can reasonably be placed on the principle. It is hard, for example, to say that unemployment should be treated any differently from accidental injury or sickness when that unemployment interrupts income.

Naturally such a notion involves large sums of government expenditure which always will be difficult to fund. It also involves a large measure of State activity which is unacceptable to many on the grounds that it produces a bloated welfare state that stifles initiative and produces dependency. But there have always been two central difficulties with extending Woodhouse-type accident compensation to sickness. The first is whether earnings-related benefits without income testing are appropriate to the social security system. Many doubt that they are. And the second is whether such an extension is the best use of available funds. We are, nevertheless, likely to agree still I think with Lord Beveridge when he said in his landmark 1942 Report: "[t]he advantages of unified social security are great and unquestionable." 15

But despite the glaring social inequities and discriminations created by treating the two sets of social problems - sickness and injury - differently, there seems to be no great sense of public disquiet or agitation about this issue. I see little evidence that it registers on the political radar screen. And since accident compensation itself was hardly a reform that was ushered in by public demand, it will probably be possible to resist extending earnings-related principles to income maintenance programmes generally for quite a long time to come.

Indeed, in the New Zealand reform, concerted efforts were made to keep the two items separate in case the prospect of them being treated similarly prevented the injury reform altogether. It will be remembered that the National Government, when they enacted the scheme in 1972, did not cover non-earners. That was an extension made by the Labour Government in 1973 before the scheme started to operate. The possibility of residual actions at common law made that policy a particularly undesirable one, and it was fortunate that it was never implemented.

The question with the Woodhouse Report was whether it looked like a social welfare scheme or a social insurance scheme. And the absence of private enterprise from the administration caused a number of difficulties at the time. In the dying days of the Shipley Government there was a serious

15 Social Insurance and Allied Services (1942) Cmd 6404, para 30. 
but misguided attempt at giving the business back to the insurance companies while retaining the no fault scheme. How anyone ever thought that that could be done economically still baffles me.

But, in the formative days of the Accident Compensation Corporation, the critical agency of law reform in New Zealand was the Department of Justice headed by Dr J L Robson with his extraordinarily able Deputy Secretary, Jim Cameron. The Department of Justice saw the difficulties of the best defeating the good. The Department said this to the Gair Committee: ${ }^{16}$

The scope of accident compensation is a matter on which witnesses giving evidence at the Select Committee have differed widely. Some witnesses have criticised the line drawn between accidents and illness in the Report. As the Report itself recognises this cannot be justified on the grounds of strict logic. It is however necessary to begin somewhere and we submit that it is a poor argument against the reform that is not immediately applied to all possible circumstances. In our view a wide approach is usually to be preferred, other things being equal, but this must be tempered by a sense of realism and of cost. The history of law reform in New Zealand is largely a history of gradualism ... .

The purpose of this submission was to avoid issues concerning the relationship between accident compensation and social welfare from arising. Personal injury compensation was a law reform measure so it did not impinge on social welfare.

These confusions have not been cleared up in subsequent times, although the Royal Commission on Social Policy chaired by Sir Ivor Richardson made an attempt at it. ${ }^{17}$

Whether the idea of community responsibility will survive and nurture a new income maintenance system that is integrated and equitable seems unlikely in the immediate future. But it may happen in the long run although, as the economists say, in the long run we will all be dead. Community responsibility is a political idea and it has served its purpose well. Whether it can be made to do more work will have to await another day. I recall writing in 1977, when I was still working extensively in the field of accident compensation, that New Zealanders might be: ${ }^{18}$

... pardoned for wondering whether New Zealand's cash benefit laws are more in the nature of a lottery than a humane and rational method of maintaining income for people. The unfair and unjust discrimination results because the choice of benefit depends on the cause of the misfortune.

16 As quoted in Compensation for Incapacity, above n 6, 93.

17 Report of the Royal Commission on Social Policy (Royal Commission on Social Policy, Wellington, 1988) (1987-90) XII AJHR H2.

18 Geoffrey Palmer "Income Maintenance at the Crossroads" in Geoffrey Palmer (ed) The Welfare State Today - Social Welfare Policy in New Zealand in the Seventies (Fourth Estate Books, Wellington, 1977) 5. 
I am sad we have made little progress on the issue since then. But efforts are being made in the right direction. The present Minister for Disability Issues, the Hon Ruth Dyson, has been leading work in the Ministry of Social Development relating to the equity and coherence of governmentfunded supports for the disabled. This work appears likely to lead to the publication of a consultation paper followed by a period of public discussion. The work addresses directly the issue of iniquities between accident compensation and benefits funded from other votes. There are human rights consequences in continuing to base eligibility for support upon the manner in which the disability was acquired. But that involves different human rights norms from those dealt with in this paper. Yet those norms may exert a powerful influence on policy in the area. 